\title{
Failed spinal anaesthesia by intrathecal ropivacaine
}

\author{
Reza Aminnejad ${ }^{*}$ \\ Assistant Professor of Anaesthesiology and Critical Care ${ }^{1 *}$, Department of Anesthesiology and Critical \\ Care, Shahid Beheshti Hospital, Qom University of Medical Sciences, Qom, Islamic Republic of Iran
}

\begin{abstract}
Ropivacaine is a newly used local anaesthetic in Iran. Replacing this newer developed drug instead of older bupivacaine has many clinically significant benefits. Block failure is reported repeatedly by Iranian anaesthesiologists in spinal anaesthesia by intrathecal ropivacaine. A few theories can explain the reason for higher block failure with intrathecal ropivacaine compared with bupivacaine. Non-commitment to using intravenous sedative medications may be the most justifiable reason for this phenomenon.
\end{abstract}

Keywords: Block failure; failed spinal anaesthesia; ropivacaine; spinal anaesthesia

Use of bupivacaine for spinal anesthesia is a common practice in Iran, but this drug may produce more prolonged recovery from motor blockade compared to ropivacaine that necessitates longer PACU (post-anesthesia care unit) stay. For this reason, the interest of Iranian anaesthesiologists to use of ropivacaine is increasing steadily. Another interesting aspect for this newer drug is its relatively safer cardiovascular profile compared to bupivacaine in cases of inadvertent intravascular injection. In practical use of ropivacaine (Ropivacaine Hydrochloride Molteni; Molteni Farmaceutici) as an intrathecal anaesthetic, some anaesthesiologists report a higher rate of block failure leading to lower interest in use of this relatively safe drug. For this reason, many authors recommend repeating spinal anesthetic after the failed one. ${ }^{1}$ And in some studies, increasing the applied dose, is recommended as a remedy. ${ }^{2}$

What maybe the truth?

The truth maybe that less intense motor blockade due to intrathecal use of ropivacaine can lead to

*Correspondence: Reza Aminnejad

Email: r.aminnejad@yahoo.com

https://orcid.org/0000-0003-0439-0440

Received: $13 / 09 / 2018$

Accepted:17/11/2018

DOI: http:/doi.org/10.4038/slja.v27i1.8379

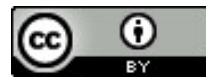

some unwanted and involuntary movements of the patient interpreted as a block failure specially by surgeons. Awake patients cannot tolerate a motionless posture for a long time. Therefore, common recommendation of complementing the regional anaesthesia with intravenous sedation may be strongly recommended in patients receiving intrathecal ropivacaine. Applying appropriate sedation program, can lead to faster onset, lesser movement of the patient specially in prolonged procedures and postoperative sedation. ${ }^{1,3}$ In previous studies, researchers have stated that plane solutions maybe responsible for this phenomenon and they have recommended to add glucose 50 $\mathrm{mg} / \mathrm{ml}$ to ropivacaine $5 \mathrm{mg} / \mathrm{ml}$ to decrease the chance of block failure. ${ }^{4}$

Another concern regarding use of intrathecal ropivacaine is its recommended dose for different lower abdominal and lower limb surgeries. It seems that usual recommended doses by manufacturer are not enough for Iranian patients. Genetic variations (racial differences) and relationship between the spread of sensory block level and dose, age and weight can explain this difference, but it necessitates further investigations in the future. ${ }^{5}$ Furthermore, drug storage conditions and cold chain effect shouldn not be ignored.

\section{References}

1. Abraham, AA., Philip, J., (2013). Failed spinal anaesthesia - management by giving a second spinal. Sri Lankan Journal of Anaesthesiology. 21(1), pp.14-19. https://doi.org/10.4038/slja.v21i1.4327 
Aminnejad. Sri Lankan Journal of Anaesthesiology: 27(1):100-101(2019)

2. Prasad, G. Priya, V. Mall, K. P. Comparative Evaluation of Three Different Doses of Spinal Isobaric Ropivacaine in Patients Undergoing Day Care Perineal Surgeries: A Randomized Doubleblind Study. Anesth Essays Res. 2018; 12: 392395

https://doi.org/10.4103/aer.AER 2918

PMid:29962604 PMCid:PMC6020554

3. D. Höhener S. Blumenthal A. Borgeat. Sedation and regional anaesthesia in the adult patient. $\mathrm{Br} \mathrm{J}$ Anaesth 2008; 100: 8-16

https://doi.org/10.1093/bja/aem342

PMid:18070783

4. P. D. W. Fettes, G. Hocking, M. K. Peterson et al. Comparison of plain and hyperbaric solutions of ropivacaine for spinal anaesthesia. Br J Anaesth 2005; 94: 107-111

https://doi.org/10.1093/bja/aei008

PMid:15516352

5. Djerada Z, Feliu C, Cazaubon Y et al. Population Pharmacokinetic-Pharmacodynamic Modeling of Ropivacaine in Spinal Anesthesia. ClinPharmacokinet 2018; 57:1135-1147 https://doi.org/10.1007/s40262-017-0617-2 PMid:29236228 